\title{
DNA mismatch repair is not disrupted in stage 0 colorectal cancer resected using endoscopic submucosal dissection
}

\author{
TOMOHIRO SUGIYAMA ${ }^{1}$, MORIYA IWAIZUMI ${ }^{2}$, MASANAO KANEKO ${ }^{1}$, SHINYA TANI ${ }^{1}$, MIHOKO YAMADE ${ }^{1}$, \\ YASUSHI HAMAYA ${ }^{1}$, TAKAHISA FURUTA ${ }^{3}$, HIROAKI MIYAJIMA ${ }^{1}$, SATOSHI OSAWA ${ }^{4}$, \\ SATOSHI BABA $^{5}$, MASATO MAEKAWA ${ }^{2}$ and KEN SUGIMOTO ${ }^{1}$ \\ ${ }^{1}$ First Department of Medicine; ${ }^{2}$ Department of Laboratory Medicine; ${ }^{3}$ Center for Clinical Research; \\ Departments of ${ }^{4}$ Endoscopic and Photodynamic Medicine, and ${ }^{5}$ Diagnostic Pathology, \\ Hamamatsu University School of Medicine, Hamamatsu, Shizuoka 431-3192, Japan
}

Received February 21, 2020; Accepted June 15, 2020

DOI: $10.3892 / \mathrm{ol} .2020 .11799$

\begin{abstract}
The frequency of deficient mismatch repair (dMMR) or microsatellite instability-high colorectal cancer (CRC) is estimated to be $\sim 15 \%$ of all patients with CRC; however, the patients reported are limited to surgical cases, and the frequency of patients exhibiting stage 0 disease is not considered, despite the currently increasing use of endoscopic techniques to cure a number of these patients. In the present study, the DNA MMR status for stage 0 patients with CRC treated using endoscopic submucosal dissection or endoscopic mucosal resection was analyzed via immunohistochemical staining of four types of proteins, namely MutL homolog 1 (MLH1), MutS homolog 2 (MSH2), MSH6 and PMS1 homolog 2 MMR system component, in adenocarcinoma specimens. Notably, none of the endoscopically resected specimens exhibited dMMR among the 41 patients diagnosed with stage 0 CRC. Since tumors harboring dMMR progress more rapidly than tumors with chromosomal instability, the present results highlight the importance of tumor resection during very early phases that exist before the promoter region of $M L H 1$ becomes hypermethylated, resulting in a loss of DNA MMR function.
\end{abstract}

\section{Introduction}

There are two forms of genomic instability that occur during colorectal cancer (CRC) progression: Chromosomal

Correspondence to: Dr Moriya Iwaizumi, Department of Laboratory Medicine, Hamamatsu University School of Medicine, 1-20-1 Handayama, Higashi-ku, Hamamatsu, Shizuoka 431-3192, Japan E-mail: iwaizumi@hama-med.ac.jp

Abbreviations: MSI-H, microsatellite instability-high; CRC, colorectal cancer; d/pMMR, deficient/proficient mismatch repair; CIN, chromosomal instability; IHC, immunohistochemistry; EMR, endoscopic mucosal resection; ESD, endoscopic submucosal dissection

Key words: CRC, DNA MMR, ESD instability (CIN) and microsatellite instability (MSI) $(1,2)$. It has been reported in 2008 that $\sim 85 \%$ of all CRC cases worldwide exhibit either numerical chromosomal alterations due to abnormal chromatid cohesion, an abnormality of the spindle assembly checkpoint or a structural abnormality; however, the definitive cause of CIN remains unknown (3-6). By contrast, one of the mechanisms leading to a 'mutator phenotype', specifically MSI, occurs due to a loss of function in the DNA mismatch repair (MMR) system and the abrogation of DNA fidelity $(7,8)$.

The DNA MMR system is comprised of two recognition complexes that detectDNAalterations (8). MutS $\alpha$, a heterodimer of the MMR proteins MutS homolog 2 (MSH2) and MSH6, recognizes base-base mismatches and insertion/deletion (I/D) loops of $<2$ nucleotides, while I/D loops of $>2$ nucleotides are recognized by MutS $\beta$, an MSH2-MSH3 heterodimer (8). Germline pathogenic variants in human MMR genes, including MSH2, MSH6, MutL homolog 1 (MLH1) and PMS1 homolog 2 MMR system component (PMS2), or germline deletions of epithelial cell adhesion molecule (EPCAM), that induce the constitutional methylation of the $M S H 2$ promoter leading to epigenetic silencing of $M S H 2$, which is associated with Lynch syndrome, and the inactivation of the DNA MMR system by somatic pathogenic variants or the hypermethylation of human MLH1 can result in MSI-high (MSI-H) CRC (8). Therefore, MMR-deficient tumors are typically identified using immunohistochemistry (IHC) to detect the loss of protein expression of $\geq 1$ MMR proteins (such as MLH1, MSH2, MSH6 and PMS2), and MSI testing can be used to identify MSI-H, as the loss of functional mutations and/or silencing via hypermethylation of DNA MMR genes causes instability within microsatellite regions (8).

Colorectal tumors exhibiting deficient (d)MMR/MSI-H possess certain unique characteristics; they tend to be located within the right colon, and their histopathological features are poorly differentiated with mucinous features and marked lymphocytic infiltration (9-12). Several studies have reported that patients with stage II-III CRC with proficient (p)MMR can benefit from fluorouracil (5-FU) treatment; however, patients with tumors that have lost their DNA MMR function do not benefit, as 5-FU incorporated in the DNA is typically 
recognized by the DNA MMR system, leading to cytotoxicity (13-17).

A previous study has revealed that patients with stage IV CRC with dMMR/MSI-H tumors benefit more strongly from programmed cell death-1 (PD-1) blockade than those with proficient pMMR or non-MSI-H tumors that retain DNA MMR function (18), as hypermutable dMMR/MSI-H tumor cells produce various types of neoantigens and induce radical $\mathrm{T}$ helper 1 cytotoxic immune responses under PD-1 blockade $(18,19)$. Therefore, understanding the frequency of patients with $\mathrm{dMMR} / \mathrm{MSI}-\mathrm{H}$ CRC at each clinical stage is important for the selection of an appropriate treatment.

The frequency of patients with $\mathrm{dMMR} / \mathrm{MSI}-\mathrm{H} \mathrm{CRC}$ has been previously estimated to be $\sim 15 \%$ by some groups in some western countries in the 2000s (20). However, recent data have revealed that among 2,439 surgically resected primary CRC cases in Japan, the frequency of patients with MSI-H is $5.9 \%$ for stages $0-$ I, $8.9 \%$ for stage II, $4.0 \%$ for stage III and $3.7 \%$ for stage IV (21), which is similar to the frequencies of patients with $\mathrm{dMMR} / \mathrm{MSI}-\mathrm{H}$ reported in China (5.7\% for stage I, $9.9 \%$ for stage II, $4.2 \%$ for stage III and $2.5 \%$ for stage IV) and South Korea (4.7\% for stage I, $4.6 \%$ for stage II, $5.2 \%$ for stage III and not analyzed for stage IV) $(22,23)$. While examining the aforementioned data, the following observations were made: i) All the patients in these reports were limited to surgical cases, and ii) the reports did not consider the frequency of patients with stage 0 disease, despite the fact that the number of patients who are being treated using endoscopic techniques is increasing (24). Additionally, to the best of our knowledge, the frequency of patients with $\mathrm{dMMR} / \mathrm{MSI}-\mathrm{H}$ in stage 0 lesions that can be endoscopically resected has not been previously reported. Therefore, little is known regarding the frequency of dMMR/MSI-H among patients with early CRC who undergo endoscopic resection, despite knowing that DNA MMR deficiency occurs during colorectal tumor initiation or at a very early stage of tumor progression (8). Additionally, as the majority of sporadic dMMR tumors possess the $B R A F$ V600E somatic pathogenic variant, which is an important marker of a poor prognosis in addition to $M L H 1$ hypermethylation $(8,20,22)$, it is important to characterize these parameters to allow for the implementation of optimal treatment strategies.

In the present study, IHC was used to evaluate the DNA MMR status of stage 0 colorectal tumors that were resected using endoscopic submucosal dissection (ESD) or endoscopic mucosal resection (EMR).

\section{Patients and methods}

Patients. From the 66 patients with colorectal neoplasia who underwent endoscopic resection using ESD (63 patients) orEMR (3 patients of adenoma) at the Hamamatsu University Hospital (Hamamatsu, Japan) between April 2015 and March 2020, the DNA MMR tumor status was evaluated using IHC in 41 patients who had been pathologically diagnosed with stage 0 colorectal adenocarcinoma according to pathologic tumor node metastasis staging of colorectal carcinoma (American Joint Committee on Cancer, 8th edition) (25) (Fig. 1). All patients provided written informed consent, and the present study was approved by the Institutional Review Board of the Hamamatsu University School of Medicine (approval no. 16-084), which confirmed that the study was in accordance with the ethical guidelines of the Helsinki Declaration. The clinical characteristics of the patients (age, sex, reason for undergoing colonoscopy, lifestyle, previous personal history and family history of CRC) are shown in Table I. Tumor location, size and shape, as well as pathological features, were recorded at the time of colonoscopy and are shown in Table II. Microscopic features were divided into five types: i) Tubular adenoma; ii) adenocarcinoma with tubular adenoma occupying $\leq 50 \%$ of the adenocarcinoma component; iii) adenocarcinoma with tubular adenoma occupying $>50 \%$ of the adenocarcinoma component; iv) adenocarcinoma and v) sessile serrated adenoma/polyp (SSA/P). Tumors with microscopic features of types ii), iii) or iv) including a cancer component, were further examined using IHC to identify the status of DNA MMR expression.

Endoscopic surgery. Colorectal ESD was indicated for the following lesions requiring an endoscopic en bloc resection: i) Lesions for which an en bloc resection using a snare EMR would be difficult to apply, such as non-granular laterally spreading tumors (LST-NG), particularly LST-NG pseudo-depressed type tumors, lesions with a VI-type pit pattern, carcinoma with shallow T1 submucosal (SM) invasion, large depressed-type tumors and large protruded-type lesions suspected of being carcinomas; ii) mucosal tumors with submucosal fibrosis; iii) sporadic localized tumors in patients with chronic inflammation, such as ulcerative colitis; and iv) local residual or recurrent early carcinomas after endoscopic resection (24). EMR was performed in cases where ESD was initially scheduled but EMR was subsequently found to be preferable based on endoscopic observations made on the day of treatment. ESD was performed using an S-O clip ${ }^{\circledR}$ (Zeon Medical Inc.), DualKnife ${ }^{\mathrm{TM}}$ (Olympus Corporation) or the Clutch Cutter ${ }^{\circledR}$ (Fujifilm Holdings Corporation). EMR was performed using the Captivator II (Boston Scientific Corporation). EMR and ESD were performed by board-certified fellows of the Japan Gastroenterological Endoscopy Society working at the Hamamatsu University Hospital.

IHC staining. Tissues were collected under the supervision of an experienced pathologist. Staining for the expression of $4 \mathrm{MMR}$ proteins (MLH1, MSH2, PMS2 and MSH6) was performed using $10 \%$ formalin-fixed for $6-48 \mathrm{~h}$ at room temperature, paraffin-embedded blocks cut into $4-\mu \mathrm{m}$ thick serial sections. The slides were stained using an automated procedure. Briefly, the slides were dewaxed by heating at $55^{\circ} \mathrm{C}$ for $30 \mathrm{~min}$, followed by three 5 -min washes using xylene. Subsequently, the tissues were rehydrated using a series of 5-min washes in 100, 95 and $80 \%$ ethanol, and distilled water. Endogenous peroxidase activity was blocked by treatment with $3 \%$ hydrogen peroxide for $10 \mathrm{~min}$ at room temperature. Following incubation with Protein Block reagent [StartingBlock ${ }^{\mathrm{TM}}$ (TBS) Blocking Buffer; cat. no. 37542; Thermo Fisher Scientific Inc.] for $5 \mathrm{~min}$ at room temperature and washing with TBS twice, the slides were incubated with the following mouse monoclonal antibodies: Anti-MLH1 (clone G168-728; 1:50; cat. no. 554073 BD Biosciences), anti-MSH2 (clone FE11; 1:10; cat. no. NA27; Merck KGaA), anti-PMS2 (clone A16-4; 1:50; cat. no. 556415; BD Biosciences) and anti-MSH6 (clone 44/MSH6;1:20; 
Table I. Clinical characteristics of patients $(n=41)$.

\begin{tabular}{|c|c|}
\hline Characteristics & Values \\
\hline Median age (range), years & $71.2(44-84)$ \\
\hline \multicolumn{2}{|l|}{ Sex, n $(\%)$} \\
\hline Male & $27(65.85)$ \\
\hline Female & $14(34.15)$ \\
\hline \multicolumn{2}{|l|}{ Purpose of colonoscopy, n (\%) } \\
\hline Screening & $3(7.32)$ \\
\hline Anemia & $1(2.44)$ \\
\hline FOB & $21(51.22)$ \\
\hline CT/PET abnormality & $2(4.88)$ \\
\hline Post-CRC operation & $6(14.63)$ \\
\hline Bloody stool & $6(14.63)$ \\
\hline Abnormal bowel movement & $2(4.88)$ \\
\hline \multicolumn{2}{|l|}{ Cigarette smoking, n (\%) } \\
\hline Never & $17(41.46)$ \\
\hline Former & $19(46.34)$ \\
\hline Current & $5(12.20)$ \\
\hline \multicolumn{2}{|l|}{ Alcohol intake, g/day, n (\%) } \\
\hline 0 & $26(63.41)$ \\
\hline $0-20$ & $9(21.95)$ \\
\hline $21-40$ & $0(0.00)$ \\
\hline$\geq 41$ & $4(9.76)$ \\
\hline Unknown & $2(4.88)$ \\
\hline \multicolumn{2}{|l|}{ History of cancer, $\mathrm{n}(\%)$} \\
\hline+ & $10(24.39)$ \\
\hline- & $31(75.61)$ \\
\hline \multicolumn{2}{|l|}{ Family history, n (\%) } \\
\hline No family history & $12(29.27)$ \\
\hline FDR & $16(39.02)$ \\
\hline SDR & $5(12.20)$ \\
\hline Unknown & $8(19.51)$ \\
\hline
\end{tabular}

FOB, fecal occult blood; FDR, first-degree relative; SDR, second-degree relative; CRC, colorectal cancer; CT, computed tomography; PET, positron emission tomography.

cat. no. 610918; BD Biosciences) for $30 \mathrm{~min}$ at room temperature, and then incubated with dextran polymer conjugated with goat anti-mouse immunoglobulin $\mathrm{G}$ and horseradish peroxidase (ChemMate Envision kit; Dako; Agilent Technologies, Inc.) for $30 \mathrm{~min}$ at room temperature. The antigen-antibody complex was visualized using 3,3'-diaminobenzidine tetrahydrochloride and was counterstained with hematoxylin for $1 \mathrm{~min}$ at room temperature using an autostainer (Histostainer; Nichirei Biosciences Inc.). The slides were examined by a light microscope (magnifications, x100 and x400).

Evaluation of MMR status. The MMR status was evaluated as previously reported (26). Briefly, tumors were considered to be negative for MLH1, MSH2, PMS2 or MSH6 expression when there was a complete absence of nuclear staining in the tumor cells, while nuclear staining of normal colonic crypt epithelium
Table II. Pathological features of patients $(n=41)$.

\begin{tabular}{|c|c|}
\hline Features & $\mathrm{n}(\%)$ \\
\hline \multicolumn{2}{|l|}{ Location } \\
\hline Cecum & $4(9.76)$ \\
\hline Ascending colon & $7(17.07)$ \\
\hline Transverse colon & $2(4.88)$ \\
\hline Descending colon & $2(4.88)$ \\
\hline Sigmoid colon & $10(24.39)$ \\
\hline Rectum & $16(39.02)$ \\
\hline \multicolumn{2}{|l|}{ Side location } \\
\hline Right & $13(31.71)$ \\
\hline Left & $28(68.29)$ \\
\hline \multicolumn{2}{|l|}{ Morphology } \\
\hline LST-G (Homo) & $6(14.63)$ \\
\hline LST-G (Mix) & $8(19.51)$ \\
\hline LST-NG (Flat) & $7(17.07)$ \\
\hline LST-NG (PD) & $1(2.44)$ \\
\hline Protruded type & $18(43.90)$ \\
\hline Superficial elevated type & $1(2.44)$ \\
\hline \multicolumn{2}{|l|}{ Tumor size } \\
\hline$<10 \mathrm{~mm}$ & $2(4.88)$ \\
\hline $10-20 \mathrm{~mm}$ & $13(31.71)$ \\
\hline $20-30 \mathrm{~mm}$ & $13(31.71)$ \\
\hline$>30 \mathrm{~mm}$ & $12(29.27)$ \\
\hline Piecemeal resection & $1(2.44)$ \\
\hline \multicolumn{2}{|l|}{ Pathology } \\
\hline Adenocarcinoma in adenoma & $19(46.34)$ \\
\hline Adenocarcinoma with adenoma & $7(17.07)$ \\
\hline Adenocarcinoma & $15(36.59)$ \\
\hline
\end{tabular}

LST-G/NG, granular/non-granular laterally spreading tumor; PD, pseudo-depressed.

adjacent to the tumor, lymphoid cells and stromal cells served as internal positive controls (Fig. 2A). Tumors lacking MLH1, MSH2, PMS2 or MSH6 expression were considered to possess a dMMR status. As MLH1 is required to stabilize PMS2, but PMS2 is not required to stabilize MLH1, tumors lacking both MLH1 and PMS2 expression exhibit a loss of MLH1 functionally, followed by PMS2 destabilization. When the loss of both MSH2 and MSH6 expression is detected, this indicates that MSH2 functional loss is followed by MSH6 degradation, as MSH2 is required to stabilize MSH6 (26). Tumors with maintained expression levels of MLH1, MSH2, PMS2 and MSH6 were considered to possess a pMMR status. For all cases, the diagnoses were confirmed under the supervision of an experienced pathologist.

\section{Results}

Confirmation of appropriate IHC staining for DNA MMR proteins in $C R C$. As shown in Fig. 2, a patient with a germline $M L H 1$ pathogenic variant determined by direct sequencing possessed a tumor lacking both MLH1 and 
Patients performed ESD/EMR $(n=66)$

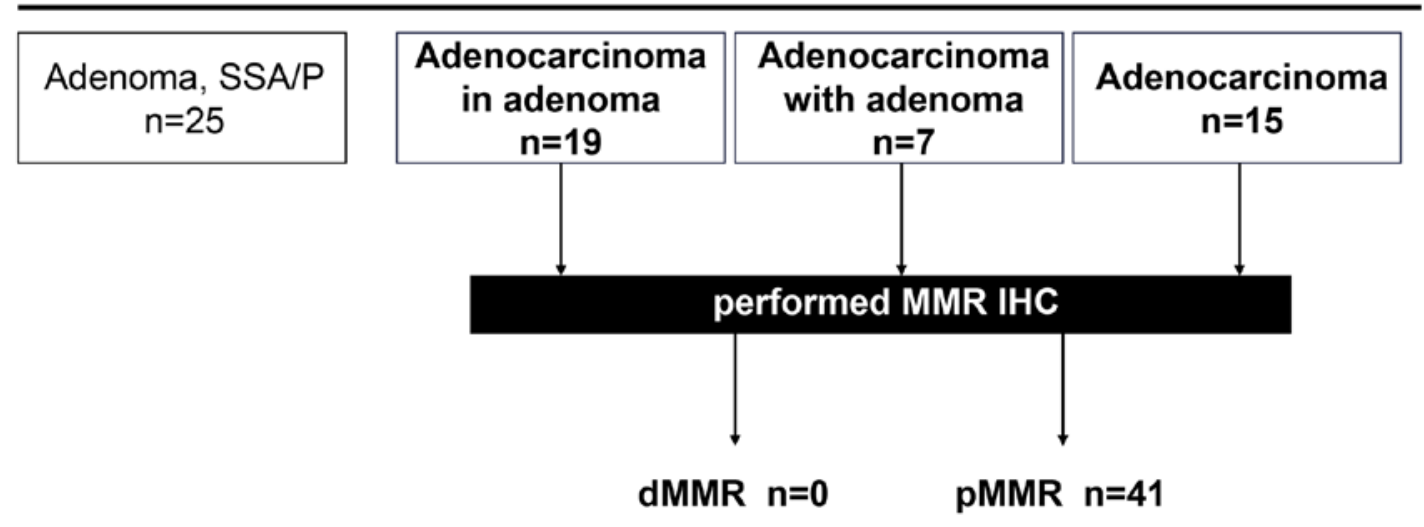

Figure 1. Patients with colorectal cancer whose tissues were analyzed using IHC for DNA MMR proteins. The flow chart presents the cancer history of all the individuals whose tissues were analyzed using IHC for DNA MMR proteins between April 2015 and March 2020, and provides a delineation of the results. ESD, endoscopic submucosal dissection; EMR, endoscopic mucosal resection; SSA/P, serrated adenoma/polyp; d/pMMR, deficient/proficient mismatch repair; IHC, immunohistochemistry.

PMS2 expression (Fig. 2B), and another patient with a tumor lacking MSH2 and MSH6 expression, and a suspected disruption of MSH2, possessed a germline $\mathrm{MSH} 2$ pathogenic variant (Fig. 2C). A third patient with sporadic advanced (Fig. 2D) and stage 0 CRC (Fig. 2E) without germline pathogenic variants of the DNA MMR genes possessed a tumor exhibiting the expression of all four analyzed MMR. The present results indicated that the current IHC method functions appropriately, and IHC was subsequently performed on early stage CRC specimens resected using ESD or EMR (Fig. 2E).

DNA MMR system is not disrupted in very early stage CRC specimens resected using ESD. Prior to endoscopic resection, consent was obtained from 66 patients, including 3 who underwent EMR and 63 who underwent ESD. In one patient, the tumor was large and the operability was poor, ultimately requiring a piecemeal resection. Among the 66 patients, 25 cases were histologically diagnosed as non-adenocarcinoma ( 3 cases of SSA/P and 22 cases of adenoma) and 41 cases as adenocarcinoma (Fig. 1). Among the 41 patients with adenocarcinoma, the number of patients with tumors in the left-sided colorectum (descending colon, sigmoid colon and rectum) is higher compared with those with tumors in the right-sided colon (cecum, ascending colon and transverse colon) (Table II), which is similar to previous reports (27-30).

As tumor MSI testing and/or IHC staining of MMR proteins for screening of Lynch syndrome is currently performed for patients with CRC (31), IHC staining of MMR proteins was performed in the 41 cases diagnosed with colorectal adenocarcinoma. Notably, none of the 41 endoscopically resected specimens of early stage CRC exhibited a dMMR status (Fig. 1).

\section{Discussion}

Once dMMR occurs, affected tumors develop more rapidly compared with those tumors that progress via the CIN pathway; tumors possessing dMMR progress within 1-3 years, while CIN tumors progress over decades (32). Therefore, the detection and resection of CRC at a very early stage is important for a complete treatment. Notably, the present study has revealed that DNA MMR function was not disrupted in stage 0 CRC. To the best of our knowledge, although the frequencies of tumor dMMR among patients with advanced-stage CRC have been previously reported (21-23), the MMR status of endoscopically resected, very early stage $\mathrm{CRC}$ has not been previously reported.

The first step for MSI/dMMR in sporadic CRC is epigenetic silencing of the $M L H 1$ gene through the hypermethylation of both its promoters $(33,34)$. Menigatti et al $(35)$ reported that $70 \%$ of the pre-cancerous aberrant crypt foci (ACF) lesions are methylated at the promoter region of $M L H 1$, suggesting that most ACF may have lost their ability to express the MLH1 protein, and this occurs in early stage CRC. However, when the aforementioned data (35) were more carefully examined, the median methylation levels for the $M L H 1$ gene were considered to be so low that the downregulation of MLH1 protein expression was likely limited to single cells or crypts, as noted by another study (36), in which it was further speculated that these alterations are very difficult to identify using IHC. Although there may be a time lag between $M L H 1$ promoter methylation and the loss of MLH1 protein expression, the present results suggested that the resection of tumors prior to the loss of MLH1 expression may reduce the likelihood of recurrence, which was not shown in the present study; however, if the resected tumor is diagnosed as dMMR, careful surveillance will be required.

From the point of view of the occurrence of dMMR, patients with pre-cancerous lesions, including patients with SSA/P with cytological dysplasia (SSAD), require careful surveillance after resection. Among the three main types of serrated lesions, namely hyperplastic polyps, traditional serrated adenoma (TSA) and SSA/P, TSA is reportedly associated with KRAS mutations and DNA methylation (37). During progression to $\mathrm{SSA} / \mathrm{P}$, a $B R A F$ gene mutation is thought to occur first, followed by the expression of a $\mathrm{CpG}$ island methylator phenotype (38). It must be noted that previous clinical reports have demonstrated that MSI-H/dMMR has not been identified in hyperplastic polyps, TSA or SSA/P, but has been reported in SSAD only $(39,40)$. Additionally, SSAD is the only pre-cancerous colorectal lesion in which $M L H 1$ is 
A
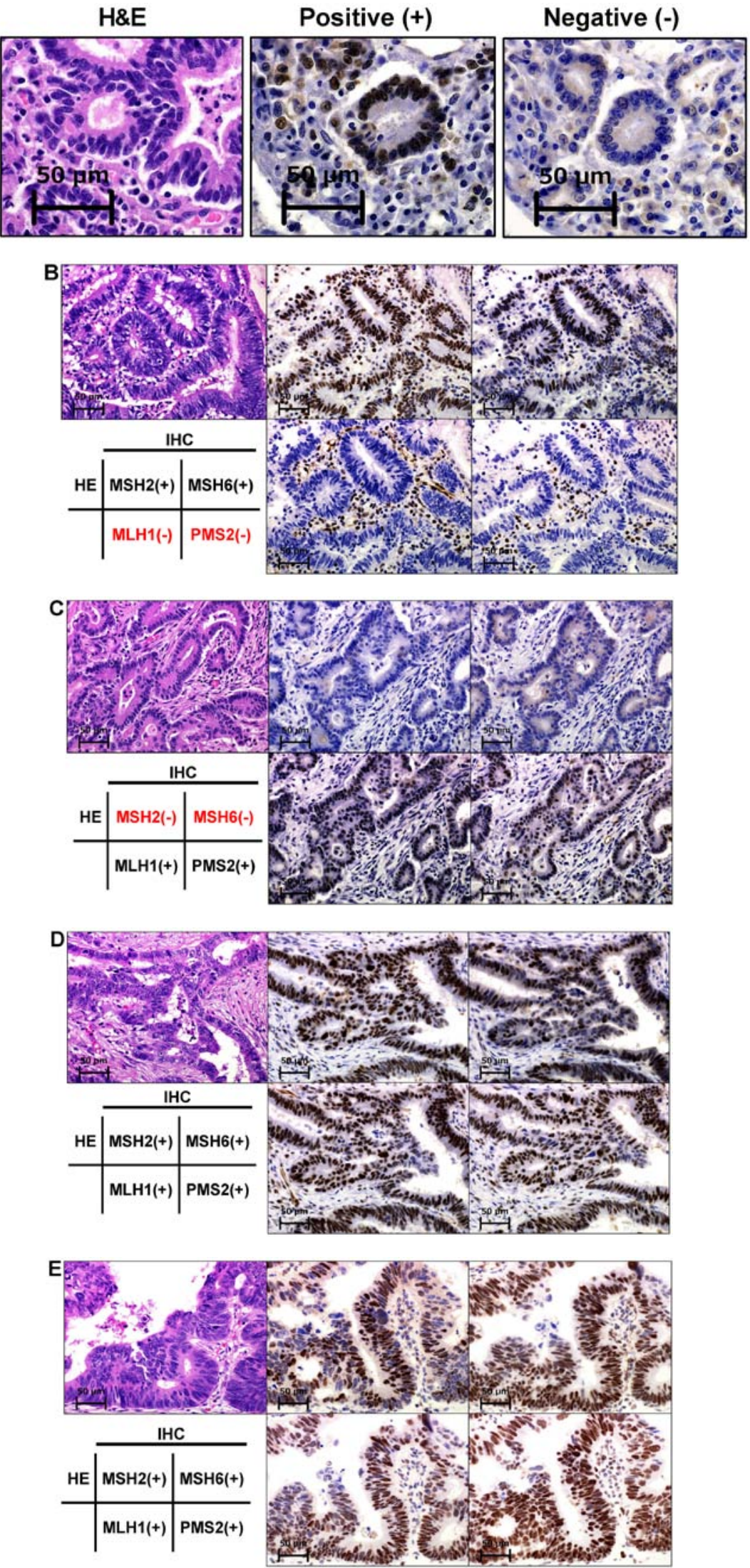

Figure 2. IHC staining of DNA MMR proteins in tissues from patients with colorectal cancer. (A) Tumors were considered negative for MLH1, MSH2, PMS2 or MSH6 expression when there was a complete absence of nuclear staining within the tumor cells, while positive staining was confirmed in normal epithelial cells and lymphocytes used as controls. Tumors lacking MLH1, MSH2, PMS2 or MSH6 expression were considered to possess a dMMR status, while tumors that maintained the expression of MLH1, MSH2, PMS2 and MSH6 were considered to exhibit a pMMR status. (B) A patient with a germline $M L H 1$ pathogenic variant possessed a tumor lacking both MLH1 and PMS2 expression. (C) A patient with a tumor lacking MSH2 and MSH6 expression and a suspected disruption of MSH2 possessed a germline $M S H 2$ pathogenic variant. A patient with (D) sporadic advanced and (E) endoscopically resected early stage CRC without a germline pathogenic variant in the DNA MMR genes presented a tumor that expressed all four analyzed MMR proteins. Scale bar, $50 \mu \mathrm{m}$. IHC, immunohistochemistry; H\&E, hematoxylin and eosin; MMR, mismatch repair; MLH1, MutL homolog 1; MSH2/6, MutS homolog 2/6; PMS2, PMS1 homolog 2 MMR system component. 
methylated (41). Furthermore, the frequency of MSI is reportedly low in Japan $(9,42,43)$, and it is possible that no cases were observed in the present study as this was not measured.

The present study presents some limitations: i) IHC for DNA MMR was performed only for cancerous lesions and not pre-cancerous lesions; ii) DNA was not extracted for a mutation search; and iii) the methylation profile was not evaluated. These points require further investigation in future studies. However, to the best of our knowledge, the present study is the first to focus on the MMR status in endoscopic resection cases, and it may represent the first step towards the use of dMMR status evaluation to help select the appropriate treatment.

In conclusion, dMMR was evaluated in endoscopically resected early stage CRC specimens, and dMMR was not detected in any of the cases. Regarding the development and progression of CRC, the results of the present study suggested that changes in MMR may not be involved in early tumor development, and the current findings are important for future medical care and understanding the pathophysiology of CRC. Future molecular biology and molecular genetic studies should further clarify the present findings.

\section{Acknowledgements}

Not applicable.

\section{Funding}

The present study was supported by the Japan Society for the Promotion of Science (KAKENHI grant no. 19K08392), the Takeda Science Foundation and Hamamatsu University School of Medicine (HUSM) Grant-in-Aid.

\section{Availability of data and materials}

All data generated or analyzed during this study are included in this published article.

\section{Authors' contributions}

MI conceived the study. SB performed and evaluated the immunohistochemistry data. MI, TS, MK, ST, MY, YH, TF, $\mathrm{HM}, \mathrm{SO}, \mathrm{MM}$ and $\mathrm{KS}$ analyzed and interpreted the data. TS, MI, HM, MM and KS drafted the manuscript and revised it critically for important intellectual content. All authors read and approved the final manuscript.

\section{Ethics approval and consent to participate}

The present study was approved by the Ethics Committee of Hamamatsu University School of Medicine (approval no. 16-084), and all the patients provided written informed consent.

\section{Patient consent for publication}

Not applicable.

\section{Competing interests}

The authors declare that they have no competing interests.

\section{References}

1. Lengauer C, Kinzler KW and Vogelstein B: Genetic instabilities in human cancers. Nature 396: 643-649, 1998.

2. Kinzler KW and Vogelstein B: Lessons from hereditary colorectal cancer. Cell 87: 159-170, 1996.

3. Iwaizumi M, Shinmura K, Mori H, Yamada H, Suzuki M, Kitayama Y,Igarashi H, Nakamura T, Suzuki H, Watanabe Y, et al: Human Sgo1 downregulation leads to chromosomal instability in colorectal cancer. Gut 58: 249-260, 2009.

4. Kahyo T, Iwaizumi M, Shinmura K, Matsuura S, Nakamura T, Watanabe Y, Yamada H and Sugimura H: A novel tumor-derived SGOL1 variant causes abnormal mitosis and unstable chromatid cohesion. Oncogene 30: 4453-4463, 2011.

5. Matsuura S, Kahyo T, Shinmura K, Iwaizumi M, Yamada $H$, Funai K, Kobayashi J, Tanahashi M, Niwa H, Ogawa H, et al: SGOL1 variant $\mathrm{B}$ induces abnormal mitosis and resistance to taxane in non-small cell lung cancers. Sci Rep 3: 3012, 2013.

6. Grady WM: Genomic instability and colon cancer. Cancer Metastasis Rev 23: 11-27, 2004.

7. Grilley M, Holmes J, Yashar B and Modrich P: Mechanisms of DNA-mismatch correction. Mutat Res 236: 253-267, 1990.

8. Grady WM and Carethers JM: Genomic and epigenetic instability in colorectal cancer pathogenesis. Gastroenterology 135: 1079-1099, 2008.

9. Ishikubo T, Nishimura Y, Yamaguchi K, Khansuwan U, Arai Y, Kobayashi T, Ohkura Y, Hashiguchi Y, Tanaka Y and Akagi K: The clinical features of rectal cancers with high-frequency microsatellite instability (MSI-H) in Japanese males. Cancer Lett 216: 55-62, 2004.

10. Kadowaki S, Kakuta M, Takahashi S, Takahashi A, Arai Y, Nishimura Y, Yatsuoka T, Ooki A, Yamaguchi K, Matsuo K, et al: Prognostic value of KRAS and BRAF mutations in curatively resected colorectal cancer. World J Gastroenterol 21: 1275-1283, 2015

11. Lochhead P, Kuchiba A, Imamura Y, Liao X, Yamauchi M, Nishihara R, Qian ZR, Morikawa T, Shen J, Meyerhardt JA, et al: Microsatellite instability and BRAF mutation testing in colorectal cancer prognostication. J Natl Cancer Inst 105: 1151-1156, 2013.

12. Nitsche U, Friess H, Agha A, Angele M, Eckel R, Heitland W, Jauch KW, Krenz D, Nüssler NC, Rau HG, et al: Prognosis of mucinous and signet-ring cell colorectal cancer in a population-based cohort. J Cancer Res Clin Oncol 142: 2357-2366, 2016.

13. Ribic CM, Sargent DJ, Moore MJ, Thibodeau SN, French AJ, Goldberg RM, Hamilton SR, Laurent-Puig P, Gryfe R, Shepherd LE, et al: Tumor microsatellite-instability status as a predictor of benefit from fluorouracil-based adjuvant chemotherapy for colon cancer. N Engl J Med 349: 247-257, 2003.

14. Carethers JM, Smith EJ, Behling CA, Nguyen L, Tajima A, Doctolero RT, Cabrera BL, Goel A,Arnold CA, Miyai K, et al: Use of 5-fluorouracil and survival in patients with microsatellite-unstable colorectal cancer. Gastroenterology 126: 394-401, 2004.

15. Tajima A, Hess MT, Cabrera BL, Kolodner RD and Carethers JM: The mismatch repair complex hMutS alpha recognizes 5-fluorouracil-modified DNA: Implications for chemosensitivity and resistance. Gastroenterology 127: 1678-1684, 2004.

16. Iwaizumi M, Tseng-Rogenski S and Carethers JM: DNA mismatch repair proficiency executing 5-fluorouracil cytotoxicity in colorectal cancer cells. Cancer Biol Ther 12: 756-764, 2011.

17. Tajima A, Iwaizumi M, Tseng-Rogenski S, Cabrera BL and Carethers JM: Both hMutS $\alpha$ and hMutS $\beta$ DNA mismatch repair complexes participate in 5-fluorouracil cytotoxicity. Plos One 6: e28117, 2011.

18. Le DT, Durham JN, Smith KN, Wang H, Bartlett BR, Aulakh LK, Lu S, Kemberling H, Wilt C, Luber BS, et al: Mismatch repair deficiency predicts response of solid tumors to PD-1 blockade. Science 357: 409-413, 2017.

19. Le DT, Uram JN, Wang H, Bartlett BR, Kemberling H, Eyring AD, Skora AD, Luber BS, Azad NS, Laheru D, et al: PD-1 blockade in tumors with mismatch-repair deficiency. N Engl J Med 372: 2509-2520, 2015.

20. Boland CR and Goel A: Microsatellite instability in colorectal cancer. Gastroenterology 138: 2073-2087.e3, 2010.

21. Fujiyoshi K, Yamamoto G, Takenoya T, Takahashi A, Arai Y, Yamada M, Kakuta M, Yamaguchi K, Akagi Y, Nishimura Y, et al: Metastatic pattern of stage IV colorectal cancer with high-frequency microsatellite instability as a prognostic factor. Anticancer Res 37: 239-247, 2017. 
22. Guo TA, Wu YC, Tan C, Jin YT, Sheng WQ, Cai SJ, Liu FQ and $\mathrm{Xu}$ Y: Clinicopathologic features and prognostic value of KRAS, NRAS and BRAF mutations and DNA mismatch repair status: A single-center retrospective study of 1,834 Chinese patients with Stage I-IV colorectal cancer. Int J Cancer 145: 1625-1634, 2019.

23. Kim CG, Ahn JB, Jung M, Beom SH, Kim C, Kim JH, Heo SJ, Park HS, Kim JH, Kim NK, et al: Effects of microsatellite instability on recurrence patterns and outcomes in colorectal cancers. Br J Cancer 115: 25-33, 2016

24. Tanaka S, Kashida H, Saito Y, Yahagi N, Yamano H, Saito S, Hisabe T, Yao T, Watanabe M, Yoshida M, et al: JGES guidelines for colorectal endoscopic submucosal dissection/endoscopic mucosal resection. Dig Endosc 27: 417-434, 2015.

25. Liu Q, Luo D, Cai S, Li Q and Li X: P-TNM staging system for colon cancer: Combination of P-stage and AJCC TNM staging system for improving prognostic prediction and clinical management. Cancer Manag Res 10: 2303-2314, 2018.

26. Kawazoe A, Shitara K, Kuboki Y, Bando H, Kojima T, Yoshino T, Ohtsu A, Ochiai A, Togashi Y, Nishikawa H, et al: Clinicopathological features of 22C3 PD-L1 expression with mismatch repair, Epstein-Barr virus status, and cancer genome alterations in metastatic gastric cancer. Gastric Cancer 22: 69-76, 2019.

27. Shiga H, Ohba R, Matsuhashi T, Jin M, Kuroha M, Endo K, Moroi R, Kayaba S and Iijima K: Feasibility of colorectal endoscopic submucosal dissection (ESD) carried out by endoscopists with no or little experience in gastric ESD. Dig Endosc 29 (Suppl 2): 58-65, 2017.

28. Iacopini F, Saito Y, Bella A, Gotoda T, Rigato P, Elisei W, Montagnese F, Iacopini G and Costamagna G: Colorectal endoscopic submucosal dissection: Predictors and neoplasm-related gradients of difficulty. Endosc Int Open 5: E839-E846, 2017.

29. Lee EJ, Lee JB, Lee SH and Youk EG: Endoscopic treatment of large colorectal tumors: Comparison of endoscopic mucosal resection, endoscopic mucosal resection-precutting, and endoscopic submucosal dissection. Surg Endosc 26: 2220-2230, 2012

30. Saito Y, Fukuzawa M, Matsuda T, Fukunaga S, Sakamoto T, Uraoka T, Nakajima T, Ikehara H, Fu KI, Itoi T, et al: Clinical outcome of endoscopic submucosal dissection versus endoscopic mucosal resection of large colorectal tumors as determined by curative resection. Surg Endosc 24: 343-352, 2010.

31. Benson AB III, Venook AP, Al-Hawary MM, Cederquist L, Chen YJ, Ciombor KK, Cohen S, Cooper HS, Deming D, Engstrom PF, et al: NCCN Guidelines Insights: Colon Cancer, Version 2.2018. J Natl Compr Canc Netw 16: 359-369, 2018.

32. Nguyen LH, Goel A and Chung DC: Pathways of colorectal carcinogenesis. Gastroenterology 158: 291-302, 2020.

33. Toyota M, Ahuja N, Ohe-Toyota M, Herman JG, Baylin SB and Issa JP: CpG island methylator phenotype in colorectal cancer. Proc Natl Acad Sci USA 96: 8681-8686, 1999.

34. Kane MF, Loda M, Gaida GM, Lipman J, Mishra R, Goldman H, Jessup JM and Kolodner R: Methylation of the hMLH1 promoter correlates with lack of expression of hMLH1 in sporadic colon tumors and mismatch repair-defective human tumor cell lines. Cancer Res 57: 808-811, 1997.
35. Menigatti M, Truninger K, Gebbers JO, Marbet U, Marra G and Schär P: Normal colorectal mucosa exhibits sex- and segment-specific susceptibility to DNA methylation at the hMLH1 and MGMT promoters. Oncogene 28: 899-909, 2009.

36. Shen L, Kondo Y, Rosner GL, Xiao L, Hernandez NS, Vilaythong J, Houlihan PS, Krouse RS, Prasad AR, Einspahr JG, et al: MGMT promoter methylation and field defect in sporadic colorectal cancer. J Natl Cancer Inst 97: 1330-1338, 2005.

37. McCarthy AJ, Serra S and Chetty R: Traditional serrated adenoma: An overview of pathology and emphasis on molecular pathogenesis. BMJ Open Gastroenterol 6: e000317, 2019.

38. Nazemalhosseini Mojarad E, Kuppen PJ, Aghdaei HA and Zali MR: The $\mathrm{CpG}$ island methylator phenotype (CIMP) in colorectal cancer. Gastroenterol Hepatol Bed Bench 6: 120-128, 2013.

39. O'Brien MJ, Yang S, Mack C, Xu H, Huang CS, Mulcahy E, Amorosino $M$ and Farraye FA: Comparison of microsatellite instability, $\mathrm{CpG}$ island methylation phenotype, BRAF and KRAS status in serrated polyps and traditional adenomas indicates separate pathways to distinct colorectal carcinoma end points. Am J Surg Pathol 30: 1491-1501, 2006.

40. Murakami T, Akazawa Y, Yatagai N, Hiromoto T, Sasahara N, Saito T, Sakamoto N, Nagahara A and Yao T: Molecular characterization of sessile serrated adenoma/polyps with dysplasia/carcinoma based on immunohistochemistry, next-generation sequencing, and microsatellite instability testing: a case series study. Diagn Pathol 13: 88, 2018.

41. Oono Y, Fu K, Nakamura H, Iriguchi Y, Yamamura A, Tomino Y, Oda J, Mizutani M, Takayanagi S, Kishi D, et al: Progression of a sessile serrated adenoma to an early invasive cancer within 8 months. Dig Dis Sci 54: 906-909, 2009.

42. Asaka S, Arai Y, Nishimura Y, Yamaguchi K, Ishikubo T, Yatsuoka T, Tanaka Y and Akagi K: Microsatellite instability-low colorectal cancer acquires a KRAS mutation during the progression from Dukes' A to Dukes' B. Carcinogenesis 30: 494-499, 2009

43. Ikeda M, Yamanaka T, Yamazaki K, Yamaguchi K, Muro K, Kusumoto T, Uetake H, Sato T, Kato T, Nishina T, et al: Validation study of the 12-gene Recurrence Score (RS) in patients (pts) with stage II and III colon cancer (CC) without adjuvant chemotherapy; Sunrise Study. Ann Oncol 26 (Suppl 4): iv104, 2015.

This work is licensed under a Creative Commons Attribution-NonCommercial-NoDerivatives 4.0 International (CC BY-NC-ND 4.0) License. 